\title{
A Review Approaches to Identify Enteric Bacterial Pathogens
}

\author{
Jafar Amani ${ }^{1}$; Seyed Ali Mirhosseini ${ }^{1}$; Abbas Ali Imani Fooladi ${ }^{1, *}$ \\ ${ }^{1}$ Applied Microbiology Research Center, Baqiyatallah University of Medical Sciences, Tehran, IR Iran \\ ${ }^{*}$ Corresponding author: Abbas Ali Imani Fooladi, Applied Microbiology Research Center, Baqiyatallah University of Medical Sciences, Tehran, IR Iran. Tel: +98-2182482568, Fax: +98- \\ 2188068924, E-mail: Imanifouladi.a@gmail.com
}

Received: January 12, 2014; Revised: March 10, 2014; Accepted: April 5, 2014

\begin{abstract}
Context: Diarrhea is a common disease across the world. According to WHO, every year about two billion cases of diarrhea are reported in the world. It occurs mainly in the tropical regions and is a main cause of morbidity and mortality, particularly in young children and adults.

Evidence Acquisition: One of the major causes of diarrheal diseases is bacteria; detection of pathogenic bacteria is a global key to the prevention and identification of food-borne diseases and enteric infections (like diarrhea).

Conclusions: Therefore, development of rapid diagnostic methods with suitable sensitivity and specificity is very important about this infectious disease. In this review, we will discuss some of the important diagnostic methods.

Keywords:Diarrhea; Methods; Morbidity
\end{abstract}

\section{Context}

Bacterial pathogens and their toxins cause illnesses, which spread throughout the population. Some bacteria are producing enterotoxins such as cholera toxin, the heat-labile or heat-stable enterotoxins produced by Escherichia coli. Others produce cytotoxins like shiga toxins produced by Shigella, which damage cells. Both of them can cause diarrheal diseases $(1,2)$. When pathogenic bacteria overcome host microbiome of normal flora, diarrhea develops (3). In 1980s, the main mortality rate of diarrhea was approximately 4.6 million per year, but it has decreased to 1.6-2.1 million since then. Most of these deaths occur in infants and young children under the age of 5 years in developing countries. Diarrhea has a lot of symptoms such as nausea, vomiting, fever, and abdominal pain. Important risk factors of diarrhea consist of age, gastric acidity, antibiotics, immunosuppression, and poor sanitation (4). One kind of this syndrome is travelers' diarrhea (TD) that is the most common cause of disability among international travelers to developing countries. Nowadays, infectious diarrhea has become one of the main health problems worldwide.

\section{Evidence Acquisition}

A rapid detection method, including identification of the pathogens in population is critical in the disease control (5). The major causes of TD are E. coli, Shigella spp., Campylobacter spp., Salmonella spp., Aeromonas spp., Plesiomonas spp., and non-cholera Vibrios. Since 1970s, enterotoxigenic E. coli (ETEC) has been the most important pathogen responsible for TD (6). Novel and important ob- jectives in identification of the enteric bacteria are development of efficient, rapid, and simple methods to detect microorganisms $(7,8)$. We could classify rapid methods into modified conventional methods, biosensors, immunological methods, and nucleic acid based assays, which are being described in this article.

\section{Results}

\subsection{Conventional Detection Methods}

In these methods, detection of bacteria and viruses mainly depends on the culture of the food sample (using microbiological media), biochemical identification of bacterial genera, or cell culture techniques (9). These methods are sensitive and inexpensive, but they are both time- and material-consuming due to its initial enrichment (a minimum of 5-7 days are required to identify an isolated colony), which typically occur in a few samples. It can delay the proper diagnosis and treatment regime, resulting in longer hospital stays (10). Culture is named to describe the biological amplification of viable and cultivatable bacteria with manufactured growth media. Isolation of the specific bacterial species from a mixed culture, without pre-enrichment is difficult. Therefore, it is possible to use a magnetic separation assay by a magnetic separator (11). To improve conventional methods and reduce the costs, we used several modification in the preparation of samples, plating, and missing counting to provide faster and easier methods.

Copyright (C) 2015, Ahvaz Jundishapur University of Medical Sciences. This is an open-access article distributed under the terms of the Creative Commons Attribution-NonCommercial 4.0 International License (http://creativecommons.org/licenses/by-nc/4.0/) which permits copy and redistribute the material just in noncommercial usages, provided the original work is properly cited. 


\subsubsection{The Analytical Profile Index}

The analytical Profile Index (API) system is a version of conventional method that is developed for quick identification of the Enterobacteriaceae family members and other Gram-negative bacteria. This system consists of a plastic strip with 20 small reaction tubes, containing the separated compartments. The API test system is manufactured by bioMerieux Corp., Marcy Etoile, France. This assay is considered the "Gold standard" with an overall sensitivity of $79 \%$. In this technique, a reaction occurs within 24 hours. This system is very useful for identifying pathogenic Yersinia isolates and has the highest sensitivity both at the genus and at the species level (12).

\subsection{Immunological-Based Methods}

Immunodetection has become a broadly used method for enteric bacteria because it permits for sensitive and specific detection. Immunological assay based on antibodies is a technology employed for the detection of bacterial cells, spores, viruses and toxins (13). Methods based on antigen-antibody interaction are used for the dedication of food-borne pathogens. Polyclonal and monoclonal antibodies are used in these methods. Although, the immunological detection methods are not as specific and sensitive as nucleic acid-based detection, they are faster, more powerful and have the ability to detect both contaminating organisms and their toxins that may not be expressed in the organism's genome. In this section, we will describe some of these methods (13).

\subsection{Enzyme-Linked Immunosorbent Assay}

This method is only based on immunological technique and belongs to heterogeneous assays. Enzyme-linked immunosorbent assay (ELISA) binds the specificity of antibodies and the sensitivity of simple enzyme assays by using antibodies or antigens attached with an easily assayed enzyme. ELISA is an assay similar to radioimmunoassay (RIA), but using an enzyme attached with an antigen or an antibody rather than a radioactive isotope. There are several kinds of this assay such as direct ELISA, indirect ELISA, and sandwich ELISA (14).

\subsubsection{Indirect Enzyme-Linked Immunosorbent Assay}

In this type, the target antigen is coated in a solid phase in an ELISA plate. When serum samples are added, specific antibodies will bind the coated antigen. The ELISA plates are washed to delete unbound antibodies. Antiimmunoglobulin antisera conjugated with a peroxidase enzyme are then added. When the substrate buffer is added, in positive cases the color of the substrate buffer will change. The color is measured at a defined wavelength using a spectrophotometer, which is proportional to the level of antibodies present in the sample (14).

\subsubsection{Competitive Enzyme-Linked Immunosorbent Assay}

The cELISA (Competitive ELISA) can be used to detect and quantify antibody or antigen using of a competitive method. The cELISA for detection of specific antibodies has largely replaced the iELISA in large-scale screening and serosurveillance. The cELISA offers significant advantages over an iELISA, as samples from many species may be tested without the need for species-specific enzymelabeled conjugates. Many antigens are extremely difficult or time-consuming to purify. When used in an indirect assay, they can produce high background values because of their nonspecific binding. However, relatively crude antigens may be used in the cELISA, provided that the 'detecting antibody' has the desired specificity. The principle of a competitive assay (for the antibodies detection) is competition between the test serum and the detecting antibody. Specific binding of the detecting antibody is detected by using an appropriate anti-species conjugate. Reduction in the obtained expected color is caused by binding of the antibodies in the test serum with the antigen, which prevents binding of the specific detecting antibody (Figure 1) (14).
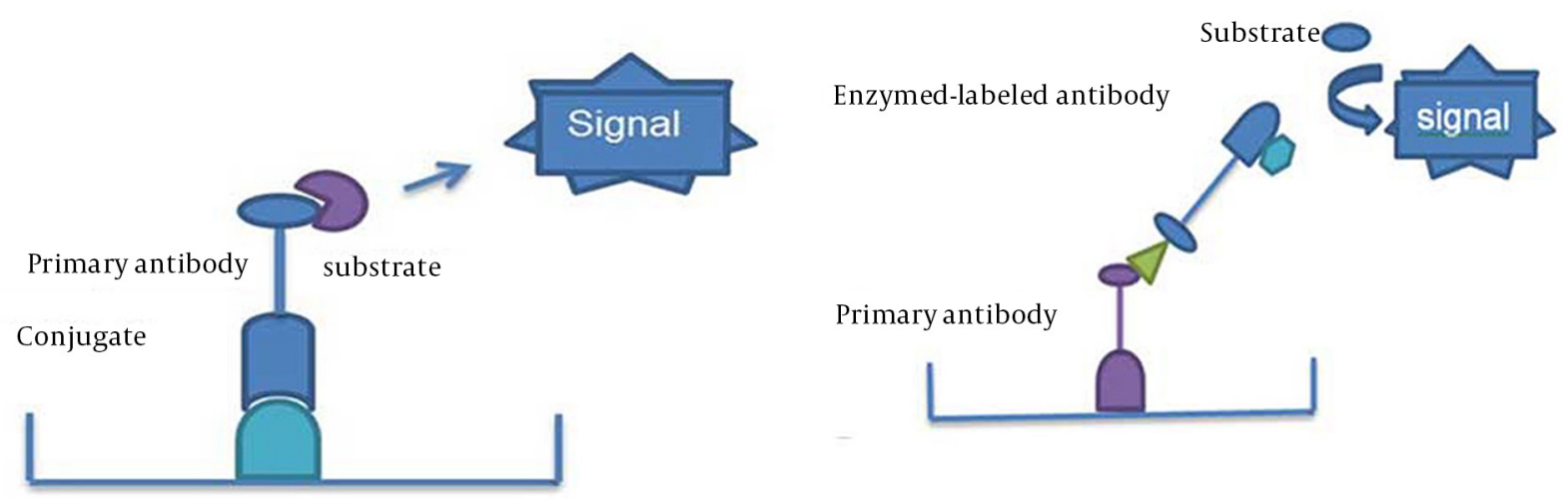

(A) Typical ELISA assay; (B) Sandwich ELISA assay. 


\subsubsection{Immunofluorescence Assay}

In this way, antibodies are labeled with a fluorescent reporter molecule whose name is fluorescein isothiocyanate (FITC). This fluorescent antibody is used to directly detect bacteria in clinical specimens and applied for rapid detection of bacteria in foods $(15,16)$. It is to be noted that polyclonal antibodies used in the procedure lack specificity and need a well-trained microbiologist to do the test. The combination of the fluorescent antibody with DEFT were used to detect E. coli: O157:H7 in milk and apple juice (16). This assay had the sensitivity of about $10^{3}$ cell $/ \mathrm{mL}$.

\subsubsection{Immunomagnetic Separation}

This method, immunomagnetic separation (IMS), utilizes paramagnetic beads (about 2-3 $\mu \mathrm{m}$ in size, about 106$108 / \mathrm{mL}$ ), which are surface activated and can be coated with antibody by incubating in the refrigerator for varying periods of time. The unattached antibody is taken away by washing. Then, the coated beads are added to a semi-liquid mixture of food that contains antigen (toxin or whole cells in Gram-negative bacteria), thoroughly mixed, and allowed to incubate for a few minutes to several hours (for reaction of antigen with antibody-coated beads). Hence, we use this assay for isolation of biological targets from samples. It has been successful in many fields, including molecular biology, immunology, and microbiology. Cells, nucleic acids, proteins or other biomolecules can be used as magnetic targets. This method reduces time and is useful for a large number of samples $(17,18)$.

\subsection{Molecular-Based Methods}

\subsubsection{Polymerase Chain Reaction}

Polymerase chain reaction (PCR) was invented in 1980. This assay can detect a single copy of a target DNA sequence, and amplifies a desired region of genome into billions of copies among a complex mixture of heterogeneous sequences (19). PCR is used for the detection of the pathogenic microorganisms in food (by utilizing nucleic acid for detection). This assay has advantages over culture and other methods (for the detection of microbial pathogens) such as specificity, sensitivity, rapidity, accuracy, and capacity to detect small amounts of target nucleic acid in a sample $(18,20)$. PCR based methods are used for the detection of a broad range of pathogens like Staphylococcus aureus (21), Listeria monocytogenes (22), Salmonella spp.(23, 24), Bacillus cereus (24), Campylobacter jejuni (25). The different forms of PCR based on their methods are real-time PCR (25-28), multiplex PCR, and reverse transcriptase PCR (RT-PCR) (23). RT-PCR is also found as multiplex RT-PCR (29-31) and real-time RT-PCR (29, 32-34).

\subsubsection{Real-Time PCR (Kinetic PCR or Quantitative real Time PCR)}

In spite of the development of alternative amplification technologies, PCR stays the most used method in the research, detection, and diagnosis of pathogens. One kind of PCR method is Real-time PCR. This method provides an opportunity for rapid detection of pathogens in food (35-38). Real-time PCR combines PCR chemistry with fluorescent probe detection of the amplified product. This method is simpler to carry out compared to conventional PCR method and its test result comes much sooner too $(39,40)$. Two kinds of chemical agents are available for real-time PCR products: fluorescent probes that bind specifically to definite DNA sequences and fluorescent dyes that intercalate into any dsDNA (41). The simplest and most cost-effective methods employed are sequence independent DNA-binding dyes such as SYBR Green I and SYBR Gold, which bound to dsDNA (42). Therefore, sensitivity and specificity, low contamination risk, ease of performance, and speed, have made real-time PCR assay an appealing alternative to conventional culture-based or immunoassay-based testing methods (39). TaqMan PCR (Fluorescent probe based real-time PCR) amplify target nucleic acid sequences from selected microbes in the samples collected from complex biological environments $(39,42)$.

\subsubsection{Multiplex PCR}

This method (simultaneous amplification of multiple gene targets ) has been designed to use two or more primer pairs directed at pathogen-specific unique sequences within a single reaction and allows the simultaneous amplification of more than one target sequence by using multiple sets of oligonucleotides to amplify two or more targets of interest (43). This method is applied for the simultaneous detection of several foodborne pathogens. For example, simultaneous detection of $E$. coli O157:H7, Salmonella spp. and S. aureus. Advantages of multiplex PCR include multiple targets that are amplified significantly without extra time, cost, or sample volume; however, there have been reports that multiplexing can reduce sensitivity compared with single reactions, (because of competition). The disadvantage of multiplex PCR is the competition between oligonucleotide pairs that can reduce PCR sensitivity (44).

\subsection{Microarrays}

Microarray is used as large scale screening systems for simultaneous identification and is very powerful tool with greater capacity (100-1000x) compared to other molecular methods (i.e. real-time PCR) that can only analyze a small number of targets. This assay is also being used for simultaneous diagnosis and detection (45). A simple microarray includes a solid surface (such as a nylon membrane, glass slide, or silicon chips) onto that is attached small quantities of ssDNA from different known bacterial species. When ssDNA from many unknown species is exposed to these array (DNA chip), strains will bind to their individual sites on the chip. 


\subsection{Detection Based on Fluorescent In Situ Hybrid- ization Assay}

Fluorescent in situ hybridization (FISH) is a molecular technique, which is sensitive, rapid, and useful for many phylogenetic, ecologic, diagnostic, and environmental studies in all fields of microbiology. In this method, a specific oligonucleotide probe is labeled with a fluorochrome for simultaneous identification of the pathogens by fluorescent microscopy. FISH has some advantages over conventional cultural methods, including avoidance of inhibitory substances; identification of viable but non-cultivable cells (VBNC); rapid availability of quantitative results; simultaneous identification of different species in the same sample; relatively low cost; and easy to do. PCR is more sensitive than FISH but sensitivity of FISH detection could be increased considerably after an enrichment step. This technique is applied in food samples for the detection of foodborne pathogens such as Staphylococcus spp., E. coli, Salmonella spp., Campylobacter spp, L. monocytogenes (46).

\subsection{Detection Based on Loop-Mediated Isothermal Amplification (LAMP) Assay}

Traditional methods for diagnosis of the disease are carried out by culturing bacteria on agar plates followed by its phenotypic and serological properties or histological examination (47). These techniques have some disadvantages such as need for previous isolation of the pathogen and insufficient sensitivity to detect low levels of pathogen (48). Molecular techniques like polymerase chain reaction (PCR) can be used to solve those problems and increase the sensitivity and specificity of the pathogen detection (49-51). Although PCR techniques are very sensitive, need for a high-precision thermal cycler has prevented these powerful methods from being widely used in the field or by private clinics as a routine diagnostic tool. Alternate isothermal nucleic acid amplification methods such as nucleic acid-based amplification (NASBA), and loop-mediated isothermal amplification (LAMP), which require only a simple heating device, have been developed for rapid and sensitive detection of target nucleic acid (52-54).

The LAMP method can produce a tremendous amount of DNA with a few copies in less than an hour with only one type of enzyme and 4-6 different specific primers without special reagents required. One advantage of LAMP over PCR is prevention of contamination, which can occur in PCR because all steps from amplification to detection are conducted within one reaction tube under isothermal conditions. Therefore, the LAMP assay is easy and requires only a water bath or heating block to provide a constant temperature as the amplification proceeds under isothermal conditions.

\subsection{Detection Based on Metagenomics Assay}

Metagenomics is based on a culture-independent study on microbial populations (microbiome) by analyzing the sample's nucleotide sequence content (55). This method amplifies and sequences the whole DNA and RNA content of a given sample, by extensive filtering of the obtained data using specific software solutions. This method is useful for random detection of existing or new pathogens. In this method, the ratio of the number of target to total amplified sequences (56), sample selection (amount of pathogens in the targeted sample), time consuming data acquisition, and data analysis time are important factors. Two limitations are currently of major concern: as the method relies on finding similarities with known pathogens, there is no solution for definition of unmatched sequences; and second, software solutions that may facilitate the interpretation of the results. To minimize these disadvantages, three solutions are currently considered, the increased pathogen load (target samples with high probability of pathogen multiplication), reducing the resulting data sets by limiting the number of targeted pathogens, and excluding the host reference sequences from data analysis and optimizing bioinformatics for "profession related" application.

\subsection{Detection Based on Pulsed Field Gel Electro- phoresis}

Pulsed field gel electrophoresis (PFGE) is useful and a gold standard for detection of food-borne zoonotic bacteria that the most important of them are S. enterica, Campylobacter spp., E .coli, Shigella spp., Vibrio cholera, and $L$. monocytogenes $(57,58)$. This technique is based on molecular assays, culture, and isolation of the bacterial strain from the food product. By this method, we can validate a full genome; however, genes with small size such as plasmids are not visible on PFGE. Therefore microbiological culture and isolation is needed for detection before the PFGE assay (59).

\subsection{Sensor-Based Pathogen Detection Systems}

\subsubsection{Biosensor}

Biosensor technology is an analytical device converting a biological response into an electrical signal. This technology is the fastest growing method for pathogen detection compared to PCR, immunology, culture methods, and gel electrophoresis. It includes a bioreceptor element such as, a microorganism, tissue, cell, enzyme, antibody, nucleic acid, biomimic, and bacteriophage (phage), which recognizes the target analyte and a transducer base on optical, acoustical, and electrochemical signal detection, for converting the recognition event into a measurable electrical signal.

\subsubsection{Phage-Based Pathogen Detection Systems}

Bacteriophage is a kind of virus that infects specific strains of bacteria. Enzymes, antibodies, nucleic acids, 
and biomimetic materials are used as bimolecular agent detectors, which have both advantages and disadvantages. Bacteriophages are biorecognition elements for the detection of different pathogenic microorganisms. Bacteriophages (phages) are viruses that attach to specific receptors on the bacterial outside and inject their genetic material inside the bacteria. These articles have a size of 20-200 $\mathrm{nm}$. They recognize the bacterial receptors by means of its tail spike proteins (e.g., the tail-spike protein of Salmonella phage P22). This recognition is highly specific. Therefore, it can be used for the typing of the bacteria and development of specific pathogen detection technologies $(18,60,61)$. The recognition of antigens on the surface of bacteria by using specific antibodies is an important subject. This approach does not need any time-consuming initial preparation of the sample; nevertheless, antibodies have problems, including their costly and cumbersome preparation.

Their limited shelf life is also important in their performance. Therefore, it was demonstrated that antibodies can be substituted with bacteriophages in the bacteria detection. Phages have several advantages in this assay such as long shelf-life, stability, and easy to isolation $(62,63)$. The bacteriophages are used in the ELISA-based assays for detection of bacterial strains. With this assay, specific strains of $S$. enterica and E. coli could be detected. The sensitivity of the assay was about $10^{5}$ bacterial cells/ well $\left(10^{6} / \mathrm{mL}\right)$, which is comparable with other ELISA tests detecting intact bacterial cells without an enrichment step. The specificity of the assay depends on the kind of bacteriophage used. Bacteriophages are abundant in their environment and their preparation is simple, rapid, cheap, and easy (63).

\subsubsection{Surface Plasmon Resonance}

A common method, which uses reflectance spectroscopy for the pathogen detection is Surface Plasmon Resonance (SPR). Application of ELISA is rapid for screening of the samples. This assay has many advantages such as selectivity, sensitivity, easy to perform, and simultaneous detection. This method can be joined to other methods such as SPR. A biosensor is an analytical tool composed of an immobilized biological ligand that 'feels' the analyte, and a physical transducer, which translates this phenomenon into an electronic signal. This assay uses reflectance spectroscopy for the pathogen detection and can detect small changes. One kind of this method is SPR-based biosensors that is used for the detection of food-borne pathogens such as L. monocytogenes, Salmonella spp., E. coli O157:H7, and C. jejuni. It demonstrated the use of multi-channel SPR biosensor for the simultaneous detection of multiple target analytes from complex mixtures (64-66).

This assay can identify concentrations in the picomolar range. Biosensors in SPR are a thin metal film between two transparent media of different refractive index, for example a glass prism and sample solution. It is one of the methods that can be used for quick toxin detection. SPR allows to study interactions in real time without labeling. It has high sensitivity (the picomolar range) and a thin metal film is utilized in SPR (gold is more suitable). One molecule binds to the other one, then attached to the surface thin metal film of the gold and changes the refractive index of solutions and finally the angle of the minimum reflected intensity shifts. SPR can directly determine the bacterial and plant toxins that have large molecular weight. In comparing ELISA to SPR, it was observed that ELISA is more sensitive than SPR, but the sample treatment with ELISA lasted six hours, while with SPR the treatment duration was only 20 minutes (Table 1 ).

\begin{tabular}{lccc}
\hline \multicolumn{3}{l}{ Table 1. Bacterial Toxin Detection in Milk, Seawater Sample (67) } \\
\hline Toxin & MW(Da) & $\begin{array}{c}\text { Type of } \\
\text { Detection }\end{array}$ & Detection Limit \\
\hline Enterotoxin B & 28,400 & direct & $1.96 \mathrm{ng} / \mathrm{mL}$ \\
\hline Enterotoxin B & 28,400 & direct & not determined \\
Enterotoxin B & 28,400 & direct & $10 \mathrm{ng} / \mathrm{mL}$ \\
Enterotoxin B & 28,400 & direct & $10 \mathrm{ng} / \mathrm{mL}$ \\
B-toxin & 35,000 & direct & not determined \\
Tetanus toxin & 150,000 & direct & $0.028 \mathrm{Lf} / \mathrm{mL}$ \\
\hline
\end{tabular}

\subsubsection{Detection Based on an Electrochemical Biosensor}

This assay is a rapid and novel electrochemical biosensor method. In this method, polypropylene microfiber membranes are coated with a conductive polypyrrole and antibody is functionalized for the biological capture and detection of enteric bacterium. The glutaraldehyde chemical can be used for attaching to conductive microfiber membranes, till a pathogen specific antibody are covalently bound to conductive microfiber membranes and then bovine serum albumin solution is used for blocking them. In this assay, use of biosensor antibodies is useful because the benefits of the antibody-antigen reaction include high binding efficiency and specificity for detection. Advantages of antibodies have made them, especially marketable for use in food materials. Then, the membranes are exposed to pathogen cells and are washed in Butterfield's phosphate buffer and added to a phosphate-buffer electrolyte solution. With the captured pathogen on the fiber surface, the resistance in the electro-textile electrode surface increases, which converts the biological recognition event into a measurable electrical signal, indicating a positive result. This method is generally less expensive than optical detection methods and is easier to use with turbid samples (68).

\subsubsection{Detection Based on Evanescent Wave Fiber-Optic Biosensors}

The development of biosensors has greatly improved the sensitivity, selectivity, and speed of the microbial pathogen and biological toxin detection. Biosensors are 
detection devices that use living organisms or biological molecules such as antibodies, nucleic acids, or enzymes, to recognize and bind target analytes in the sample matrix. After binding, the presence of the target analyte is detected by electrical signal, a colorimetric or fluorescent indicator reaction, or some other recognition response. Because the detection of microbial pathogens and biological toxins in food, water, and human specimens are difficult, this assay relies on immunological reactions for their capture or detection. It can identify such target analytes in minutes rather than days and directly from complex matrix samples using antibody-based assays, thus significantly improves the detection sensitivity, selectivity, and speed. In addition, live organism targets can be recovered from fiber-optic waveguides to determine microorganism viability, confirm their identification, and preserve as evidence.

This technology has the potential of rapid detection of microorganisms, toxins, and other analytes. Evanescent wave fiber-optic biosensors are biosensors that utilize evanescent wave detection techniques. Electro-magnetic waves propagate within an optical fiber by total internal reflection at the exposed surface. This process induces an evanescent electromagnetic field in any surrounding dielectric media, which decays exponentially with distance from the surface. When fluorescent probes are used with this system, bounded fluorophore molecules immediately adjacent to the fiber surface are strongly excited, and some of the fluorescent signals are coupled back into the optical fiber $(69,70)$.

The remaining fluorescent signals are scattered and absorbed before it can be passed through the sample.
Unbound fluorophores further from the fiber surface encounter lower field strength and are not effectively excited, thereby providing considerable protection from bulk sample fluorescence. Microorganisms and toxins such as Yersinia pestis (69), E. coli lipopolysaccharide endotoxin (70), pseudexin toxin (71), Clostridium botulinum toxin A (72), Staphylococcal enterotoxin B (73), ricin (74), Bacillus anthracis, Francisella tularensis, Escherichia coli $\mathrm{O} 157: \mathrm{H7}$, S. typhimurium (75), have been successfully detected with evanescent wave fiber-optic biosensors (see Table 2).

\subsubsection{Detection Based on Rapid Bioluminescent Methods}

These techniques are divided into two classes: 1) methods based on bioluminescent adenosine triphosphate (ATP) assay 2) methods based on bacterial bioluminescence. These methods are useful in the food industry and give their results in the shortest time.

\subsubsection{Bioluminescent Adenosine Triphosphate (ATP) Assay}

Intracellular ATP is needed for all living cells. They utilize ATP for many mechanisms during all phases of the growth. ATP is destroyed within a few minutes, therefore it can be used for detection of the microbial biomass. A rapid ATP assay based on the firefly (Photuris pyralis) was developed as a replacement for the conventional plate count methods in microbiological analysis of food. Firefly (P.pyralis) luciferase produces light with ATP and luciferin (LH2) according to this reaction: $\mathrm{LH}_{2}+\mathrm{ATP}+\mathrm{O}_{2} \mathrm{Mg}++$ $\mathrm{P}+\mathrm{AMP}+\mathrm{PPi}+\mathrm{CO}_{2}+\mathrm{h} v$.

Table 2. Examples of Analytes Detected by Evanescent Wave Fiber-Optic biosensors (76)

\begin{tabular}{lc}
\hline Target & Detection limit \\
\hline Bacillus anthracis, colony-forming units/mL & $10^{5}$ \\
\hline Francisella tularensis, colony-forming units/mL & $10^{5}$ \\
Salmonella typhimurium, colony-forming units/mL & $10^{5}$ \\
\hline Escherichia coli O157:H7, colony-forming units/mL & $10^{5}$ \\
Yersinia pestis F1 antigen, $\mathbf{n g} / \mathbf{m L}$ & 50 \\
\hline Staphylococcal enterotoxin B, pg/mL & 10 \\
Cholera toxin, ng/mL & 100 \\
E. coli lipopolysaccharide endotoxin, $\mathbf{1 0} \mathbf{~ n g / m L}$ & 50 \\
\hline Ricin, $\mathbf{n g} / \mathbf{m L}$ & \\
\hline
\end{tabular}

Table 3. Partial list of Commercially-Available, Nucleic acid-Based Assays Used in the Detection of Food-borne Bacterial Pathogens $(79,80)^{\mathrm{a}}$

\begin{tabular}{lccc}
\hline Organism & Trade Name & Assay Format & Manufacturer \\
\hline Campylobacter & GENE-TRAK & probe & Neogen \\
Escherichia coli & GENE-TRAK & probe & Neogen \\
E. coli O157:H7 & Probelia & PCR & BioControl \\
Listeria & BAX; GENE-TRAK ; AccuProbe & PCR; Probe; probe & Qualicon NeogenGEN-PROBE \\
Salmonella & GENE-TRAK BAX; Probelia; BIND & Probe; PCR; PCR; phage & Neogen; Qualicon BioControl BioControl \\
Yersinia enterocolitica & GENE-TRAK & Probe & Neogen \\
\hline a Abbreviations: PCR, polymerase chain reaction; BIND, bacterial ice nucleation diagnostic. & \\
b Adopted AOAC Official First or Final Action.
\end{tabular}


Amani Jet al.

\begin{tabular}{|c|c|c|}
\hline Organism/toxin & Assay Format & Manufacturer \\
\hline \multicolumn{3}{|l|}{ Bacillus cereus diarrhoeal toxin } \\
\hline TECRA; BCET & ELISA; RPLA & TECRA; Unipath \\
\hline \multicolumn{3}{|l|}{ Campylobacter } \\
\hline Campyslide & LA & Becton Dickinson \\
\hline Meritec-campy & LA & Meridian \\
\hline MicroScreen & LA & Mercia \\
\hline VIDAS & ELFA & bioMerieux \\
\hline TECRA & ELISA & TECRA \\
\hline \multicolumn{3}{|l|}{ C. perfringens enterotoxin } \\
\hline PET & RPLA & Unipath \\
\hline \multicolumn{3}{|l|}{ EHEC 0157:H7 } \\
\hline RIM & LA & REMEL \\
\hline E. coli $\mathrm{O} 157$ & LA & Unipath \\
\hline Prolex & LA & PRO-LAB \\
\hline Ecolex O157 & LA & Orion Diagnostica \\
\hline Wellcolex O157 & LA & Murex \\
\hline E. coli $\mathrm{O} 157$ & LA & TechLab \\
\hline $\mathrm{O} 157 \& \mathrm{H} 7$ & Sera & Difco \\
\hline Petrifilm HEC & Ab-blot & $3 \mathrm{M}$ \\
\hline Dynabeads & Ab-beads & Dynal \\
\hline EHEC-TEK & ELISA & Organon Teknika \\
\hline Assurance & ELISA & BioControl \\
\hline E. coli $\mathrm{O} 157$ & ELISA & LMD Lab \\
\hline Premier O157 & ELISA & Meridian \\
\hline E. coli $\mathrm{O} 157$ & EIA/capture & TECRA \\
\hline Quix Rapid O157 & Ab-ppt & Universal HealthWatch \\
\hline VIDAS & ELFA & bioMerieux \\
\hline \multicolumn{3}{|l|}{ Shiga toxin, Stx } \\
\hline VEROTEST & ELISA & MicroCarb \\
\hline Premier EHEC & ELISA & Meridian \\
\hline Verotox-F & RPLA & Denka Seiken \\
\hline \multicolumn{3}{|l|}{ ETEC } \\
\hline Labile toxin, LT & RPLA & Oxoid \\
\hline Stabile toxin, ST & ELISA & Oxoid \\
\hline \multicolumn{3}{|l|}{ Salmonella } \\
\hline Bactigen & LA & Wampole Labs \\
\hline Spectate & LA & Rhone-Poulenc \\
\hline Dynabeads & Ab-beads & Dynal \\
\hline CHECKPOINT & Ab-blot & KPL \\
\hline 1-2 Test & Diffusion & BioControl \\
\hline Salmonella-TEK & ELISA & Organon Teknika \\
\hline Salmonella & ELISA & GEM Biomedical \\
\hline Transia Plate Salmonella Gold & ELISA & Diffchamb \\
\hline PATH-STIK & Ab-ppt & LUMAC \\
\hline Clearview & Ab-ppt & Unipath \\
\hline UNIQUE & Capture-EIA & TECRA \\
\hline \multicolumn{3}{|l|}{ Shigella } \\
\hline Bactigen & LA & Wampole Labs \\
\hline \multicolumn{3}{|l|}{ Enterotoxin } \\
\hline SET-EIA & ELISA & Toxin Technology \\
\hline SET-RPLA & RPLA & Unipath \\
\hline TECRA & ELISA & TECRA \\
\hline VIDAS & ELFA & bioMerieux \\
\hline \multicolumn{3}{|l|}{ Vibrio cholera } \\
\hline Cholera SMART & Ab-ppt & New Horizon \\
\hline Cholera Screen & Agglutination & New Horizon \\
\hline \multicolumn{3}{|l|}{ Enterotoxin } \\
\hline VET-RPLA & RPLA & Unipath \\
\hline
\end{tabular}


Table 5. Partial List of Other Commercially Available Rapid Methods and Specialty Substrate Media for Detection of Foodborne Bacteria (79-81) ${ }^{\mathrm{a}}$

\begin{tabular}{|c|c|c|}
\hline Organism & Assay Format & Manufacturer \\
\hline \multicolumn{3}{|l|}{ Coliform/E. coli } \\
\hline Isogrid & HGMF/MUG & QA Labs \\
\hline Petrifilm & media-film & $3 \mathrm{M}$ \\
\hline SimPlate & media & Idexx \\
\hline Redigel & Media & RCR Scientific \\
\hline ColiQuik & MUG/ONPG & Hach \\
\hline LST-MUG & MPN media & Difco \& GIBCO \\
\hline CHROMagar & Medium & CHROMagar \\
\hline \multicolumn{3}{|l|}{ E. coli } \\
\hline MUG disc & MUG & REMEL \\
\hline CHROMagar & Medium & CHROMagar \\
\hline \multicolumn{3}{|l|}{ EHEC } \\
\hline Rainbow Agar & Medium & Biolog \\
\hline BCMO157:H7 & Medium & Biosynth \\
\hline $\begin{array}{l}\text { Fluorocult } \\
\text { O157:H7 }\end{array}$ & Medium & Merck \\
\hline \multicolumn{3}{|l|}{ Salmonella } \\
\hline Isogrid & HGMF & QA Labs \\
\hline OSRT & Medium/motility & Unipath (Oxoid) \\
\hline Rambach & Medium & CHROMagar \\
\hline MUCAP & C8esterase & Biolife \\
\hline XLT-4 & Medium & Difco \\
\hline
\end{tabular}

a Abbreviations: HGMF/MUG, hydrophobic grid membrane filter/4methylumbelliferyl- $\beta$-D-glucuronide; ONPG, O-nitrophenyl $\beta$-Dgalactoside; MPN, most probable number.

The sensitivity of commercially available manual or automated luminometers is less than $0.1 \mathrm{pg}$ (around 100 bacterial cells) (77). This technique can be used for milk and milk products, meat and meat products, carbonated beverages and fruit juices.

\subsubsection{Bacterial Bioluminescence}

Vibrio, Photobacterium, Alteromonas, and Xenorhabdus, are the major genera of bioluminescent bacteria (those capable of emitting light). In these bacteria, the bioluminescent reaction carried out by the enzyme luciferase. This process involves the oxidation of a long-chain aldehyde and reduction of riboflavin phosphate (FMNH2), which results in the emission of blue green light.

$\mathrm{FMNH}_{2}+\mathrm{O}_{2}+\mathrm{RCOH}$ luciferase FMN $+\mathrm{RCOOH}+\mathrm{H}_{2} \mathrm{O}+$ light (490 nm).

These properties can be used in the food industry, including the detection of specific bacterial pathogens and indicator microorganisms, spore forming organisms, lactic acid bacteria, monitoring starter culture integrity, biocide and virucide, and recovery of sublethally-injured cells. Determination of ATP by firefly luciferase is a rapid technique and is useful to detect and enumerate cells, but this assay is unable to identify bacteria. We can transfer lux genes from luminescent bacteria into specific bacteria by their bacteriophages and observe the light emissions and detect strains such as S. typhimurium, Campylobacter spp, and L. monocytogenes. The sensitivity of this method is as few as 100 cells (100 per mL). It can be used to determine Gram-positive organisms. If spores of Bacillus spp. receive lux gene, light emission is observed after germination and growth phase, which is detectable by monitoring light emission (78).

\subsection{Partial List of Commercially-Available Rapid Detection Kits}

The following text and tables list many of the commercially available rapid detection kites; they are classified by the principles underlying the procedure used (Tables 3, 4, 5).

\section{Conclusions}

Bacterial pathogens and their toxins can cause illnesses such as diarrhea and spread through population. These pathogens are causing more and more outbreaks of disease every year. Therefore, rapid and reliable detection methods are needed. Conventional methods for the detection of enteric pathogen bacteria are sensitive. However, Traditional standard culture methods require long turnaround time for enrichment and confirmation of presumptive isolates and may require several days to obtain results. These methods are based on immunochemical and nucleic acid technologies and are alternatives for conventional methods, because these methods can provide results within hours. The DNA microarrays can facilitate whole genome comparisons among diverse strains and the identification of strain-specific and lineage-specific sequences.

The conventional PCR methods, automated fluorogenic, and quantitative real-time PCR kits have been invented and become available on the market. But in the laboratories that have lower sample throughput, commercialized automated immunoassay-based methods are less expensive. Optical techniques like SPR have better sensitivity, but they are expensive and complicated. The methods based on biosensor are rapid in detecting microbial pathogens within hours or even minutes. LAMP assays, peptide nucleic acid probes, DNA microarrays, and DNA chips are more advanced and potentially new rapid methods for enteric pathogens detection. Therefore, these rapid methods have become increasingly popular among laboratories and could be accepted as cost-effective and standard methods for pathogen detection in the future.

\section{Acknowledgements}

All co-authors have read and agreed upon the contents of the manuscript and there was no financial interest to 
report. We certify that the submission is not under review at any other publication.

\section{Authors' Contributions}

Jafar Amani: wrote and revised the paper; Seyed Ali Mirhosseini: wrote the paper; and Abbas Ali Imani Fool: revised the paper.

\section{References}

1. Pawlowski SW, Warren CA, Guerrant R. Diagnosis and treatment of acute or persistent diarrhea. Gastroenterology. 2009;136(6):1874-86.

2. Guerrant RL, Kosek M, Lima AA, Lorntz B, Guyatt HL. Updating the DALYs for diarrhoeal disease. Trends Parasitol. 2002;18(5):191-3.

3. Checkley W, Buckley G, Gilman RH, Assis AM, Guerrant RL, Morris SS, et al. Multi-country analysis of the effects of diarrhoea on childhood stunting. Int J Epidemiol. 2008;37(4):816-30.

4. Kosek M, Bern C, Guerrant RL. The global burden of diarrhoeal disease, as estimated from studies published between 1992 and 2000. Bull World Health Organ. 2003;81(3):197-204.

5. Warsen AE, Krug MJ, LaFrentz S, Stanek DR, Loge FJ, Call DR. Simultaneous discrimination between 15 fish pathogens by using 16 S ribosomal DNA PCR and DNA microarrays. Appl Environ Microbiol. 2004;70(7):4216-21.

6. de la Cabada Bauche J, Dupont HL. New Developments in Traveler's Diarrhea. Gastroenterol Hepatol (N Y). 2011;7(2):88-95.

7. Deisingh AK, Thompson M. Strategies for the detection of Escherichia coli O157:H7 in foods. J Appl Microbiol. 2004;96(3):419-29.

8. Gui J, Patel IR. Recent advances in molecular technologies and their application in pathogen detection in foods with particular reference to yersinia. J Pathog. 2011;2011:310135.

9. Tebbs RS, Wong LY, Brzoska P, Petrauskene OV. Molecular technologies for Salmonella detection Salmonella distribution, adaptation, control measures and molecular technologies.; 2012.

10. Scallan E, Griffin PM, Angulo FJ, Tauxe RV, Hoekstra RM. Foodborne illness acquired in the United States--unspecified agents. Emerg Infect Dis. 2011;17(1):16-22.

11. Chow VTK, Inglis TJJ, Peng song K. Diagnostic clinical microbiology. Microb Biotechnol. 2006:539-93.

12. Peele D, Bradfield J, Pryor W, Vore S. Comparison of identifications of human and animal source gram-negative bacteria by API 20E and crystal E/NF systems. J Clin Microbiol. 1997;35(1):213-6.

13. Iqbal SS, Mayo MW, Bruno JG, Bronk BV, Batt CA, Chambers JP. A review of molecular recognition technologies for detection of biological threat agents. Biosens Bioelectron. 2000;15(11-12):549-78.

14. Vidova B, Godany A, Sturdik E. Rapid detection methods of microbial pathogens in foods-a short survey. Trnava .2008:5.

15. Swaminathan B, Ayres JC, Williams JE. Control of nonspecific staining in the fluorescent antibody technique for the detection of salmonellae in foods. Appl Environ Microbiol. 1978;35(5):911-9.

16. Swaminathan B, Feng P. Rapid detection of food-borne pathogenic bacteria. Annu Rev Microbiol. 1994;48:401-26.

17. Refseth UH, Kolpus T, Mathiesen S, Nesbakken T, Eckner K. Evaluation of a new diagnostic system utilizing magnetic beads for rapid detection of Salmonella in food samples. 2001.

18. Velusamy V, Arshak K, Korostynska O, Oliwa K, Adley C. An overview of foodborne pathogen detection: in the perspective of biosensors. Biotechnol Adv. 2010;28(2):232-54.

19. Rahmani F, Fooladi AA, Marashi SM, Nourani MR. Drug resistance in Vibrio cholerae strains isolated from clinical specimens. Acta Microbiol Immunol Hung. 2012;59(1):77-84.

20. Kumar R, Surendran PK, Thampuran N. Evaluation of culture, ELISA and PCR assays for the detection of Salmonella in seafood. Lett Appl Microbiol. 2008;46(2):221-6.

21. Riyaz-Ul-Hassan S, Verma V, Qazi GN. Evaluation of three different molecular markers for the detection of Staphylococcus aureus by polymerase chain reaction. Food Microbiol. 2008;25(3):452-9.

22. Chen Y, Knabel SJ. Multiplex PCR for simultaneous detection of bacteria of the genus Listeria, Listeria monocytogenes, and major serotypes and epidemic clones of L. monocytogenes. Appl Environ Microbiol. 2007;73(19):6299-304.

23. Choi SH, Lee SB. Development of Reverse Transcriptase-polymerase Chain Reaction of fimA Gene to Detect Viable Salmonella in Milk. J Animal Sci Technol.2004;46.

24. Perry L, Heard P, Kane M, Kim H, Savikhin S, Domínguez W, et al. Application of Multiplex Polymerase Chain Reaction to the Detection of Pathogens in Food. J Rapid Methods Autom Microbiol. 2007;15(2):176-98.

25. Ronner AC, Lindmark H. Quantitative detection of Campylobacter jejuni on fresh chicken carcasses by real-time PCR. J Food Prot. 2007;70(6):1373-8.

26. O' Grady J, Sedano-Balbas S, Maher M, Smith T, Barry T. Rapid realtime PCR detection of Listeria monocytogenes in enriched food samples based on the ssrA gene, a novel diagnostic target. Food Microbiol. 2008;25(1):75-84.

27. Malorny B, Anderson A, Huber I. Salmonella real-time PCR-Nachweis. Journal für Verbraucherschutz und Lebensmittelsicherheit. 2007;2(2):149-56.

28. Desai PT, Walsh MK, Weimer BC. Solid-phase capture of pathogenic bacteria by using gangliosides and detection with realtime PCR. Appl Environ Microbiol. 2008;74(7):2254-8.

29. Marashi SM, Bakhshi B, Fooladi AA, Tavakoli A, Sharifnia A, Pourshafie MR. Quantitative expression of cholera toxin mRNA in Vibrio cholerae isolates with different CTX cassette arrangements. J Med Microbiol. 2012;61(8):1071-3

30. Amin Marashi SM, Rajabnia R, Imani Fooladi AA, Hojati Z, Moghim S, Nasr Esfahani B. Determination of ctxAB expression in Vibrio cholerae Classical and El Tor strains using Real-Time PCR. Int J Mol Cell Med. 2013; 2(1):9-13.

31. Wolf S, Williamson WM, Hewitt J, Rivera-Aban M, Lin S, Ball A et al. Sensitive multiplex real-time reverse transcription-PCR assay for the detection of human and animal noroviruses in clinical and environmental samples. Appl Environ Microbiol. 2007;73(17):5464-70.

32. Casas N, Amarita F, de Maranon IM. Evaluation of an extracting method for the detection of Hepatitis A virus in shellfish by SYBRGreen real-time RT-PCR. Int J Food Microbiol. 2007;120(1-2):179-85.

33. Dubois E, Hennechart C, Merle G, Burger C, Hmila N, Ruelle S, et al. Detection and quantification by real-time RT-PCR of hepatitis A virus from inoculated tap waters, salad vegetables, and soft fruits: characterization of the method performances. Int J Food Microbiol. 2007;117(2):141-9.

34. Saraylu J, Mehrabadi Fallah J, Imani Fooladi AA, Sabbaghi A, Molla Aghamirzaei H, Hasankhani M. Prevalence and evaluation of toxin genes among uropathogenic Escherichia coli clinical isolates by duplex PCR. J Med Bacteriol. 2012;1(1).

35. Lisby G. Application of nucleic acid amplification in clinical microbiology. Methods Mol Biol. 1998;92:1-29.

36. Mothershed EA, Whitney AM. Nucleic acid-based methods for the detection of bacterial pathogens: present and future considerations for the clinical laboratory. Clin Chim Acta. 2006;363(12):206-20.

37. Procop GW. Molecular diagnostics for the detection and characterization of microbial pathogens. Clin Infect Dis. 2007;45 Suppl 2:S99-S111.

38. Darban-Sarokhalil D, Imani Fooladi AA, Maleknejad P, Bameri Z, Aflaki M, Nomanpour B, et al. Comparison of smear microscopy, culture, and real-time PCR for quantitative detection of Mycobacterium tuberculosis in clinical respiratory specimens. Scand J Infect Dis. 2013;45(4):250-5.

39. Espy MJ, Uhl JR, Sloan LM, Buckwalter SP, Jones MF, Vetter EA, et al Real-time PCR in clinical microbiology: applications for routine laboratory testing. Clin Microbiol Rev. 2006;19(1):165-256.

40. Fard SY, Nomanpour B, Fatolahzadeh B, Mobarez AM, DarbanSarokhalil D, Fooladi AA, et al. Hospital acquired pneumonia: comparison of culture and real-time PCR assays for detection of Legionella pneumophila from respiratory specimens at Tehran hospitals. Acta Microbiol Immunol Hung. 2012;59(3):355-65.

41. Iijima Y, Asako NT, Aihara M, Hayashi K. Improvement in the detection rate of diarrhoeagenic bacteria in human stool specimens by 
a rapid real-time PCR assay. J Med Microbiol. 2004;53(Pt 7):617-22.

42. Karlsen F, Steen HB, Nesland JM. SYBR green I DNA staining increases the detection sensitivity of viruses by polymerase chain reaction. J Virol Methods. 1995;55(1):153-6.

43. Imani FA, Iman ID, Hosseini DR, Karami A, Marashi SM.Design of a multiplex PCR method for detection of toxigenic-pathogenic in Vibrio cholerae.Asian Pac J Trop Med. 2013; 6(2):115-8.

44. Mehrabadi JF, Morsali P, Nejad HR, Imani Fooladi AA. Detection of toxigenic Vibrio cholerae with new multiplex PCR. J Infect Public Health. 2012;5(3):263-7

45. Miller MB, Tang YW. Basic concepts of microarrays and potential applications in clinical microbiology. Clin Microbiol Rev. 2009;22(4):611-33.

46. Leonard P, Hearty S, Brennan J, Dunne L, Quinn J, Chakraborty T et al. Advances in biosensors for detection of pathogens in food and water. Enzyme Microb Technol. 2003;32(1):3-13.

47. Toranzo AE, Magariños B, Romalde JL. A review of the main bacterial fish diseases in mariculture systems. Aquaculture. 2005;246(1-4):37-61.

48. Altinok I, Capkin E, Kayis S. Development of multiplex PCR assay for simultaneous detection of five bacterial fish pathogens. Vet Microbiol. 2008;131(3-4):332-8.

49. Brown LL, Iwama GK, Evelyn TPT, Nelson WS, Levine RP. Use of the polymerase chain reaction (PCR) to detect DNA from Renibacterium salmoninarum within individual salmonid eggs. Dis Aquat Organ. 1994;18:165-71.

50. Temprano A, Yugueros J, Hernanz C, Sanchez M, Berzal B, Luengo JM, et al. Rapid identification of Yersinia ruckeri by PCR amplification of yrul-yruR quorum sensing. J Fish Dis. 2001;24(5):253-61.

51. Suzuki K, Sakai DK. Real-time PCR for quantification of viable Renibacterium salmoninarum in chum salmon Oncorhynchus keta. Dis Aquat Organ. 2007;74(3):209-23.

52. Notomi T, Okayama H, Masubuchi H, Yonekawa T, Watanabe K, Amino N, et al. Loop-mediated isothermal amplification of DNA Nucleic Acids Res. 2000;28(12):E63.

53. Compton J. Nucleic acid sequence-based amplification. Nature. 1991;350(6313):91-2.

54. Zhang DY, Brandwein M, Hsuih T, Li HB. Ramification amplification: a novel isothermal DNA amplification method. Mol Diagn. 2001;6(2):141-50

55. Bexfield N, Kellam P. Metagenomics and the molecular identification of novel viruses. Vet J. 2011;190(2):191-8.

56. Palacios G, Druce J, Du L, Tran T, Birch C, Briese T, et al. A new arenavirus in a cluster of fatal transplant-associated diseases. $N$ Engl JMed. 2008;358(10):991-8.

57. Swaminathan B, Barrett TJ, Hunter SB, Tauxe RV, C. D. C. PulseNe Task Force. PulseNet: the molecular subtyping network for foodborne bacterial disease surveillance, United States. Emerg Infect Dis. 2001;7(3):382-9.

58. Boxrud D, Monson T, Stiles T, Besser J. The role, challenges, and support of pulsenet laboratories in detecting foodborne disease outbreaks. Public Health Rep. 2010;125 Suppl 2:57-62.

59. Ghodousi A, Vatani S, Darban-Sarokhalil D, Omrani M, Fooladi A Khosaravi A, et al. Development of a new DNA extraction protocol for PFGE typing of Mycobacterium tuberculosis complex. Iran J Microbiol. 2012;4(1):44-6.

60. Singh A, Glass N, Tolba M, Brovko L, Griffiths M, Evoy S. Immobilization of bacteriophages on gold surfaces for the specific capture of pathogens. Biosens Bioelectron. 2009;24(12):3645-51.

61. Xie F, Yang H, Li S, Shen W, Wan J, Johnson ML, et al. Amorphous magnetoelastic sensors for the detection of biological agents. Intermetallics. 2009;17(4):270-3.

62. Shabani A, Zourob M, Allain B, Marquette CA, Lawrence MF,
Mandeville R. Bacteriophage-modified microarrays for the direct impedimetric detection of bacteria. Anal Chem. 2008 80(24):9475-82.

63. Galikowska E, Kunikowska D, Tokarska-Pietrzak E, Dziadziuszko $\mathrm{H}$, Los JM, Golec P, et al. Specific detection of Salmonella enterica and Escherichia coli strains by using ELISA with bacteriophages as recognition agents. Eur J Clin Microbiol Infect Dis 2011;30(9):1067-73.

64. Bhunia AK, Geng T, Lathrop A, Valadez A, Morgan MT. Optical immunosensors for detection of Listeria monocytogenes and Salmonella Enteritidis from food. Optical Technologies for Industrial, Environmental, and Biological Sensing.: International Society for Optics and Photonics; 2004.

65. Koubová V, Brynda E, Karasová L, Škvor J, Homola J, Dostálek J et al. Detection of foodborne pathogens using surface plasmon resonance biosensors. Sens Actuators B Chem. 2001;74(1-3):100-5.

66. Waswa J, Irudayaraj J, DebRoy C. Direct detection of E. Coll O157:H7 in selected food systems by a surface plasmon resonance biosensor. Food Sci Technol. 2007;40(2):187-92.

67. Hodnik V, Anderluh G. Toxin detection by surface plasmon resonance. Sensors (Basel). 2009;9(3):1339-54.

68. Leonard P, Hearty S, Quinn J, O'Kennedy R. A generic approach for the detection of whole Listeria monocytogenes cells in contaminated samples using surface plasmon resonance. Biosens Bioelectron. 2004;19(10):1331-5.

69. Anderson GP, Golden JP, Ligler FS. A fiber optic biosensor: combi nation tapered fibers designed for improved signal acquisition. Biosens Bioelectron. 1993;8(5):249-56.

70. Cao LK, Anderson GP, Ligler FS, Ezzell J. Detection of Yersinia pestis fraction 1 antigen with a fiber optic biosensor.J Clin Microbiol. 1995;33(2):336-41.

71. James EA, Schmeltzer K, Ligler FS. Detection of endotoxin using an evanescent wave fiber-optic biosensor. Appl Biochem Biotechnol.1996;60(3):189-202.

72. Ogert RA, Shriver-Lake LC, Ligler FS. Toxin detection using a fiber optic-based biosensor:: Proc SPIE; 1993.

73. Ogert RA, Brown JE, Singh BR, Shriver-Lake LC, Ligler FS. Detection of Clostridium botulinum toxin A using a fiber optic-based biosensor. Anal Biochem. 1992;205(2):306-12.

74. Tempelman LA, King KD, Anderson GP, Ligler FS. Quantitating staphylococcal enterotoxin $\mathrm{B}$ in diverse media using a portable fiber-optic biosensor. Anal Biochem. 1996;233(1):50-7.

75. Anderson GP, King KD, Gaffney KL, Johnson LH. Multi-analyte in terrogation using the fiber optic biosensor. Biosens Bioelectron. 2000;14(10-11):771-7.

76. Lim DV. Detection of microorganisms and toxins with evanescent wave fiber-optic biosensors. Proceedings of the IEEE. 2003;91(6):902-7.

77. Leach FR, Webster JJ. Commercially available firefly luciferase reagents. Methods Enzymol.1986;133:51-70

78. Baker JM, Griffiths MW, Collins-Thompson DL. Bacterial bioluminescence: applications in food microbiology. J Food Prot. 1992;55(1):62-70.

79. Feldsine PT, Forgey RL, Falbo-Nelson MT, Brunelle SL. Escherichia coli O157:H7 visual immunoprecipitate assay: a comparative validation study. J AOAC Int. 1997;80(1):43-8.

80. Cox NA, Fung D, Bailey J, Hartman PA, Vasavada PC. Miniaturized kits, immunoassays and DNA hybridization for recognition and identification of foodborne bacteria. Dairy food Sanit. 1987;7.

81. Chain V, Fung D. Comparison of Redigel, Petrifilm, spiral plate system, Isogrid, and aerobic plate count for determining the numbers of aerobic bacteria in selected foods. J food prot.1991;54 